\title{
Hidden Disunities and Uncanny Resemblances: Connections and Disconnections in the Music of Lera Auerbach and Michael Nyman
} ap Sion, P.E.

\section{Contemporary Music Review}

DOI:

$10.1080 / 07494467.2014 .959275$

Published: 27/10/2014

Peer reviewed version

Cyswllt i'r cyhoeddiad / Link to publication

Dyfyniad o'r fersiwn a gyhoeddwyd / Citation for published version (APA):

ap Sion, P. E. (2014). Hidden Disunities and Uncanny Resemblances: Connections and Disconnections in the Music of Lera Auerbach and Michael Nyman. Contemporary Music Review, 33(2), 167-187. https://doi.org/10.1080/07494467.2014.959275

\footnotetext{
Hawliau Cyffredinol / General rights

Copyright and moral rights for the publications made accessible in the public portal are retained by the authors and/or other copyright owners and it is a condition of accessing publications that users recognise and abide by the legal requirements associated with these rights.

- Users may download and print one copy of any publication from the public portal for the purpose of private study or research.

- You may not further distribute the material or use it for any profit-making activity or commercial gain

- You may freely distribute the URL identifying the publication in the public portal?
}

Take down policy

If you believe that this document breaches copyright please contact us providing details, and we will remove access to the work immediately and investigate your claim. 
Hidden Disunities and Uncanny Resemblances: Connections and Disconnections in the music of Lera Auerbach and Michael Nyman

Pwyll ap Siôn

Does stylistic appropriation serve to create a sense of unity or disunity, continuity or fragmentation? Taking George Lipsitz's notion of 'families of resemblance' and intertextuality's dialogic qualities (as shown in the writings of Mikhail Bakhtin and Julia Kristeva), this article will put forward the argument that certain forms of quotation result in a kind of halfway house - an in-between state-where the text seemingly announces its own independence despite its (inter)dependence on a whole host of other intertexts. Unlike the collage-like, so-called polystylistic compositions of the late 1960s, which also used quotation, an altogether different and more deeply embedded form has developed since then, where the quoted material is integrated to a much greater extent on the surface, only to lay bare its 'difference' at a deeper level. Such 'hidden discontinuities' will be examined in relation to a single work, Lera Auerbach's Sogno di Stabat Mater (2005/2008), before applying Lipsitz's principle as a case study to Michael Nyman's oeuvre.

Keywords: Lera Auerbach's Sogno di Stabat Mater, Michael Nyman, Quotation and Intertextuality, Mikhail Bakhtin, Julia Kristeva, George Lipsitz's 'Families of Resemblance'. 


\section{Introduction}

The focus of this article will be on contemporary music from the first decade of the present century. However, I would like to begin by providing a more general context to this discussion by looking at a pop song from the 1960s. In his book Studying Popular Music, Richard Middleton analyses Procol Harum’s 1967 hit ‘A Whiter Shade of Pale' in relation to the emerging countercultural movement of the late 1960s, examining in particular how certain pop groups at that time, such as the Beatles, Cream and Pink Floyd, were increasingly drawing from a range of styles which lay beyond the pop domain in their songs. ${ }^{1}$ Such heterogeneous influences included Formatted: Highlight classical instrumentation and arrangement, avant-garde and experimental use of collage and juxtaposition, electronic manipulation and transformation of sounds, extended improvisation, and so on (see Middleton, 1990, pp. 28-9; Covach, 1997, p. 3).

Yet 'A Whiter Shade of Pale' offers a different take on the so-called 'progressive' rock style. Unlike previous tracks used by Middleton in his analysis, which appear to revel in the psychedelic interplay of incompatible opposites, Procol Harum's song manages to integrate and even synthesize a number of seemingly disparate elements. Its opening instrumental melody and harmonic pattern are drawn from a Bach Cantata (possibly his Cantata No. 140, Zion hört die Wächter singen, although others have drawn comparison with the 'Air' from the composer's Orchestral Suite No. 3). Charlie Gillett also hears Percy Sledge's 1966 hit 'When a Man Loves a Woman' imbuing the song's main vocal line, suggesting an additional 
stylistic layer — that of 'white soul' (Gillett, 1983, p. 394). ${ }_{2}^{2}$ While John Covach sees

these traits as forming part of the song's 'stylistic eclecticism' (Covach, 1997, p. 26), Middleton's analysis in fact revolves around the notion of 'how ... such a fusion [can] take place' (Middleton, 1990, p. 30). In short, he asks: what is it that allows Baroque, Rock and its various subgenres to fit together in this way? Middleton concludes that 'between [these] two codes ... there are differences but also a relatively high syntactic correlation' (Middleton, 1990, p. 31) which enables such codal connections to take place. One could describe such familial relationships as 'resemblances', to borrow a term used by sociologist George Lipsitz in a somewhat different context (Lipsitz, 1987). Lipsitz applied the term 'families of resemblance' (taken from anthropologist Michael M. J. Fisher) in relation to cultural borrowing and appropriation; this article makes a further case for its application to practices relating to musical quotation in contemporary art music.

The aesthetic dichotomy presented in Middleton's (albeit brief) survey of late 1960s progressive rock can be reduced to the following question: does stylistic appropriation in a work serve to create a sense of unity or disunity, continuity or fragmentation, or do such methods result in a kind of halfway house - an in-between state - where the text seemingly announces its own independence despite its (inter)dependence on a whole host of other intertexts? As seen from the above example, popular music was implicitly addressing such aesthetic concerns during the 1960s, but of arguably more significance was that these issues were being reflected in other areas around the same time. The journey taken by avant-garde composers such as Luciano Berio, Mauricio Kagel and Karlheinz Stockhausen towards quotation is by now a well-trodden one in many musical-historical accounts of this period: Berio most notably in the third movement of his Sinfonia (1968) for orchestra, Stockhausen 
in electronic works such as Telemusik (1966) and Hymnen (1966-67), and Kagel in his Ludwig van (1969), for various instruments (see Griffiths, 2010, pp. 167-89; Heile, 2006, 105-138; Osmond-Smith, 1985). These compositions are often described as examples of 'musical collage' (or, in Kagel's own word, 'metacollage'), which is defined by David Metzer as 'compositions that amass disparate elements, including quotations of earlier pieces, into thick, heterogeneous textures' (Metzer, 2003, p. 108).

Despite the use of such 'disparate elements', these works also sought to incorporate stabilising features to their collage-like constructions, linked together either by means of a common work (Berio's use of Mahler's Second Symphony in his Sinfonia), a shared tradition (Stockhausen's use of Japanese music in Telemusik), or a single composer (Kagel's use of Beethoven in Ludwig van). Metzer refers to these unifying principles as ways of '[connecting] elements' and '[creating] links' between past and present. However, such techniques of textual stratification and superposition could not conceal the surface impression of a kind of Tower of Babel 'cacophony' of babbling voices that were often projected by such works. As Metzer points out, '[the] incessant combining of past and present ... often appears as if it has spun out of control, the "proliferating" connections taking on a life of their own' (Metzer, 2003, p. 130). To use an analogy from Schenkerian analysis, foreground activities in such works merely masked hidden unities on the background level. In the collage works of Berio and Stockhausen, then, a final reassurance through some form of resolution is offered, even though it is never directly 'spelled out'.

This strand of contemporary music from the late 1960s that used quoted material was thus based on a kind of 'polystylistic' pluralism: the employment of a wide and eclectic range of quotations from all manner of musical styles and periods. 
Part of its effect has been related to the notion of 'parody' in contemporary music. For example, Linda Hutcheon cites Peter Maxwell Davies's Antechrist as a suitable example of parody in twentieth-century music: its opening quotes from the thirteenthcentury motet 'Deo Confitemini Domino' before, as Hutcheon puts it, being 'broken down and superimposed on related plainsong fragments — which the new context turns ironically inside out' (Hutcheon, 1985, p. 15). Whether intended as parody, irony or homage, polystylistic quotation continued into the 1970s and 80s, and ranged from Alfred Schnittke's String Quartet No. 3 (1983), which opens with quotes from a disparate set of sources (Orlando di Lasso, Beethoven and Shostakovich's 'D-S-C-H' motive), or David Del Tredici's cycle of works based on Lewis Carroll's Alice in Wonderland stories, to John Zorn's Forbidden Fruit (1987) for string quartet and turntable.

Case Study 1: Quotation and (dis)connection in Lera Auerbach's Sogno di Stabat Mater

Procol Harum's smooth synthesis of old and new may be said to lie at the very opposite end of this spectrum - there is no attempt in 'A Whiter Shade of Pale' to frame quotation in any anachronistic or ironic way, as indeed was also the case with similar attempts at 'fluid' popular fusions, such as Wendy Carlos's Switched-On Bach. ${ }^{3}$-However, an altogether different and more deeply embedded form of quotation may be said to have developed since the collage compositions of the 1960s, where the quoted material appears integrated to a much greater extent on the surface, only to lay bare its différance on a deeper level. Disunities that operate at this deeper 
level may be said to signal a more subversive form of postmodern 'alienation', and this article will set out first of all to show how this is evoked in a single work, Lera Auerbach's Sogno di Stabat Mater (2005/2008). The final section of this article will propose a reading of this work as an example of a composition which assimilates a single source into its stylistic web, based on George Lipsitz's concept of 'families of resemblance' and suggest ways in which this principle can be applied to an entire body of works using composer-Michael Nyman's music as the basis for as a second case study. First of all, the this article will describe and analyse the use of quotation in Auerbach's Sogno di Stabat Mater.

Composed in 2008, the Sogno di Stabat Mater is a composition based on a composition. In addition to its previous and obvious engagement with Giovanni Pergolesi's well-known Stabat Mater (1736), Auerbach also reworks a previous composition, Dialogues on Stabat Mater, for solo violin, viola, vibraphone and string orchestra (2005). As suggested by the latter's title, the aim of the work is to establish a dialogue between itself and Pergolesi, as explained by Auerbach in a note on the work:

[in writing this piece] I hoped to create ... a dialogue [and] in this dialogue I did not so much want to proceed from the aesthetic differences in culture and harmonic language between the $18^{\text {th }}$ and $21^{\text {st }}$ centuries, but rather from their similarities which, incidentally, are much more fascinating. (Auerbach, 2012)

Therefore the idea of establishing a common set of stylistic features — of families of resemblance- - between the precursor text and the new work, forms part of Auerbach's 
intentions, with the aim of blurring distinctions that exist between the two. Such 'blurring' is further reflected in some of the composer's verbal indications provided in the score, such as the direction in the vibraphone part that 'the harmonies should not sound clean, but rather distorted, layers upon layers, clouded like forgotten memories' (Auerbach, 2008, p. 4). Critic Joshua Kosman also noticed such textual ambiguities when he referred to the 'ghostly, blurring memories of the [Pergolesi] source' (Kosman, 2010). The title of the work, Sogno di Stabat Mater (Dream of the Stabat Mater), also evokes a state in-between fantasy and reality or dream and nightmare. 4 Indeed, Lawrence Kramer's use of 'the uncanny' in music, which draws on Sigmund Freud to describe forms of quotation in postmodern music, seems especially appropriate and will be discussed in more detail later (Kramer 2002, pp. 258-88; see also Kramer, 1990, pp. 203-9). Auerbach sets up ‘a dialogue across time’ where her own musical language (and by extension the language of late twentieth and early twenty-first century art music as symbolised by her music) is connected to Baroque patterns and processes in general and Pergolesi's appropriation of them in particular. This notion of 'dialogue' has featured in various writings on intertextuality, especially Mikhail Bakhtin and Julia Kristeva, and it is worth considering how their theories relate to forms of musical quotation, which also set up 'dialogues' of various kinds.

Bakhtin's thoughts on the dialogic nature of language are presented in his The Dialogic Imagination and in Kristeva's essay 'Word, Dialogue and Novel'. Bakhtin was one of the first to draw upon the notion of dialogue and dialogic expression. In his essay 'Epic and Novel', he contrasts the epic narrative with the novel, arguing that the former displays the presence of a singular, unquestionable authorial voice while the latter is either diaglossic (double-voiced) or polyglossic (multi-voiced). In its incorporation of elements such as laughter, irony, humour and parody the novel 
becomes 'dialogized' and stylistically multidimensional. Important formative genres in this respect were the Socratic dialogues, whose central image (unlike the epic) was that of a 'speaking and conversing man', or Menippean satire, which was 'dialogic, full of parodies and travesties, multi-style, and does not fear elements of bilingualism' (Bakhtin, 1981, p. 26). Bakhtin elaborates on these ideas in his 'Discourse in the Novel', where he refers to the dialogization of language 'as the basic distinguishing features of the stylistic of the novel' (Bakhtin, 1981, p. 263). He views the novel's representation as a kind of social heteroglossia that gives writing its dialogic quality. ${ }^{5}$ Elaborating on the Bakhtinian notion of the ideological space of texts, in her essay 'Word, Dialogue, Novel' Kristeva sets out to demonstrate the way in which texts '[exteriorise] linguistic dialogue' (Kristeva, 1986, p. 37). Thus for Kristeva and Bakhtin, dialogue is the only sphere possible for the life of language-it can only exist on this dialogical plane. According to Kristeva, dialogical structures '[appear] only in the light of a text elaborating itself as ambivalent in relation to another text' (Kristeva, 1980, p. 87). Such 'dialogue and ambivalence' is embedded in the use of quotation, upon which Bakhtin dwells in his essay 'Discourse in the Novel':

The word in language is half someone else's. It becomes 'one's own' only when the speaker populates it with his own intention, his own accent, when he appropriates the word, adapting it to his own semantic and expressive intention [yet] not all words for just anyone submit equally easily to this appropriation, to this seizure and transformation into private property: many words stubbornly resist, other remain alien, sound foreign in the mouth of the one who appropriated them ... as if they put themselves in quotation marks against the will of the speaker. Language is not a natural medium that passes freely and easily into the private property of the speaker's intentions; it is populated-overpopulated-with the intentions of others. (Kristeva, 1980, pp. 293-4) 
As shown in the following analysis, Auerbach's dialogue with the past in the Sogno di Stabat Mater functions as an effective musical equivalent to Bakhtin's and Kristeva's theory of textual signification. The Sogno operates in this way on a number of levels - formal and stylistic, generic and specific, gestural and emotional. Figure 1 (see below) highlights general textual correspondences between the Sogno and Pergolesi's Stabat Mater. Connections may be found from the very opening of the work. Auerbach's Sogno begins with a descending five-note figure between solo violin and viola, which moves crablike from $\mathrm{B}$-flat to $\mathrm{D}$, a minor sixth below, via Fsharp, G and C-sharp (see Figure 2). The pattern is first stated in direct imitation between the two parts - a typically Baroque technique, which also sets up the notion of a 'dialogue' from the very outset — before the viola line gradually drifts away from the violin, possibly indicating an 'uneasy' dialogue between past and present. This figure is very similar to (though not exactly the same as) a figure heard in the fifth movement of Pergolesi's setting, 'Quis est homo' (bar 13), minus one of its pitches (C-sharp). The figure also shares some affinity with a bass line from the seventh movement of Pergolesi's work, 'Eja Mater', to which this analysis will return later. The Sogno therefore starts with a fragment from the original source rather than a complete quote. This fragment takes on the expressive character of a Baroque affect and its application: a descending, chromatically inflected, sigh-like, figure, presented imitatively between two parts. The connection between the two works in the opening of the Sogno may therefore be described as 'implicit'.

\section{[insert Figure 1 here]}


Figure 1 Textual correspondences between Lera Auerbach's Sogno di Stabat Mater and Pergolesi's Stabat Mater.

[insert Figure 2 here]

Figure 2 The opening five-note figure in Auerbach based on Pergolesi's 'Quis est homo' (bar 13).

Such connections are made more explicit between bars 28-55 (Letters D-F), when Auerbach takes fragments from the final section of the Stabat Mater, 'Quando corpus morietur', followed by an excerpt from the 'Amen' section. Figure 3a shows the viola at bars 40-42 quoting the triadic figure from the 'Amen' section (both are played forte), while in Figure 3b, bars 4-5 from 'Quando corpus morietur' are transferred from violin and viola to vibraphone at bars 49-54. (As the most antithetical sound to Baroque music in the Sogno, the vibraphone's role is often one of 'the outsider', commenting as if from afar on the dialogues that take place between violin, viola and string orchestra, and interjecting in ghost-like fashion when the relationship between the new work and its original source is at its most strained.) Previous to this section, at Letter D, slowly unfolding imitative lines are heard over a pedal C, but this does not appear to constitute a direct quote; rather it takes on the stylistic and expressive character of Baroque music. The introduction of more specific quotes (as shown in Figures 3a and b) starts to reinforce more obvious connections between the two works.

[insert Figures 3a \& 3b here] 
Figure 3a Violin and Viola at bars 40-2 (Auerbach) and the beginning of Pergolesi's ‘Amen' section.

Figure 3b Violin solo at bars 49-52, Vibraphone at bars 53-4 (Auerbach), and the opening from Pergolesi's 'Quando corpus morietur'.

The more direct, if fragmentary, quotes in Figures $3 \mathrm{a}$ and $3 \mathrm{~b}$ lead, in the following section, to the most explicit relationship between Auerbach and Pergolesi: an unaltered quote from the first movement of the Stabat Mater (bars 12-21 and 4347) in bars 56-70 (Letters G-H) of the Sogno (see Figure 4 for the first four bars in each case). The connection between the two works is made even more obvious at this point, not only due to the quotation's length (at 13 bars it is the most extensive single quote in the piece), but also because Auerbach chooses to use the most well-known section from Pergolesi's work, retaining all its lines, tempo and dynamics. In certain respects, then, the previous sections, which draw on fragments and snippets of Pergolesi, act as a kind of prelude to this moment.

\section{[insert Figure 4 here]}

Figure 4 Direct quotation from the Stabat Mater (opening) at Letter G of Auerbach's Sogno.

From this point onwards, Auerbach appears to treat the pre-existing material as a repository upon which to draw in a more or less free and inventive manner. The Sogno's engagement with the original material thus becomes more dialogic in nature, almost as if the quotation marks that were present in the previous sections have been removed. At bars 71-78 (Letter I) a melodic line in the vibraphone appears to be drawn from the opening bass line of the Stabat Mater, but very much in the spirit of a 
free variation. At Letter J a solo viola melody makes use of the pitch contour from the opening line of movement 10, 'Fac ut portem' (see Figure 5a), but the rhythmic character of the original has been removed. At Letter $\mathrm{K}$ the violin solo draws on the melodic shape of 'Quando Corpus', as seen earlier in Figure 3b.

\section{[insert Figures 5a \& b here]}

Figure 5a Viola solo at Letter J (Auerbach) and Pergolesi’s ‘Fac ut portem'.

Figure 5b Bass line descent at Letter K (Auerbach) and 'Quis est homo' (Pergolesi).

The gradual bass-line descent in K (viola) and L (strings), from E-flat to G, as shown in Fig. 5b, may be viewed as a composite version of the bass-line heard in the fifth movement of the Stabat Mater, 'Quis est homo': all the pitches minus the final G can be found in violin 1, bar 1 (E-flat, D), and cello/bass, bars 1-3, descending chromatically from C to A-flat. The Sogno's use of composite patterns and layering fragments by simultaneously drawing on more than one quotation adds to a sense of free variation. This bass line is also, of course, an example of the chaconne bass commonly found in music from this period, and therefore, like many imitative passages, functions as part of a larger set of generic Baroque patterns heard in the Sogno. Another generic pattern appears between bars 111-118 (Letter M), where Auerbach uses a string figuration similar to the one heard in movement 9, 'Sancta mater', further reinforcing the Sogno's connections with Baroque idioms.

Letters N-U in the Sogno recapitulate previous material-letter N recaps letter K, and Letters Q-S repeats D-E — but these reappearances are 'disrupted' by moments of chromatic saturation (at bars 131-4 and 152-68 respectively). The Sogno thus 'quotes itself' by repeating previous material, but the nature of the 'original' 
material is called into question by what is done to it and the way in which Auerbach leads these quotations into new, more dissonant territories. If these moments bring conflict into the dialogue, then bars 173-198 (Letters V-X) provide some form of resolution. As shown in Figure 6, the melodic line in violin and viola solo bears some similarity to the bass line from the seventh movement, 'Eja mater' (bars 50-55), which uses the following pitches: Eb-B-C-[Ab]-F\#-G. The pedal note in both pieces - $\mathrm{C}$ in Auerbach, $\mathrm{G}$ in Pergolesi-also reinforces this association, in addition to the legato articulation.

\section{[insert Figure 6 here]}

Figure 6 Melodic line in Violin and Viola solo at Letter V (Auerbach) and 'Eja mater' bars 50-55 (Pergolesi).

The final sections of the Sogno attempt to draw together a number of fragments through a kind of dialogic layering process. For example, Letter Y superposes the bass line from the opening of the Stabat Mater, the melodic line from the opening of 'Quando corpus morietur', plus the figure from 'Eja Mater' (see Figure 6), as shown in Figure 7. A rhythmic figure introduced at $\mathrm{Z}$ is also similar to the cadential figure heard at the end of Pergolesi's first movement, suggesting a further blurring between overt quotation and implicit reference. Auerbach's use of Pergolesi material is arguably at its most fecund here, and the interplay between the two becomes highly inventive.

\section{[insert Figure 7 here]}

Figure 7 Melodic line in Viola solo at Letter Y (Auerbach) and the Violin solo at the beginning of 'Quando corpus morietur' (Pergolesi). 
Finally, the reintroduction of the 'Eja Mater' motive from bar 226 until the end makes its connection with the motive heard at the beginning of the Sogno clear (see, again, Figure 2). There is a definite sense of a return to the opening but it is a return with a difference that results from the introduction and development of a number of dialogic layers, as shown above and summarised in Figure 1.

Auerbach's references increasingly take on the character of ghostly quotations as the work draws to its close, and this ties in with postmodern approaches to quotation in general. Postmodernists adopt signs from the cultural past to suit their own ends, and Lawrence Kramer has drawn comparison with the figure of the revenant to articulate this sense of 'past present'. Defined by him as a 'ghost, a phantom, one who haunts, who returns, who walks again', Kramer sees revenants imbuing postmodern compositions with literally a spirit of the past, but one which at the same time eschews or resists historical awareness or consciousness (Kramer, 2002, p. 263). Kramer observes that '[the] sameness of the revenant is the form in which that difference is overcome, the form in which the past lives on - but not as it was, not exactly. The same returns in order to live on-differently' (Kramer, 2002, p. 264). In Auerbach's Sogno, the same does indeed return to live on, but differently.

Further parallels can be drawn here between Kramer's use of the uncanny and Kristeva's concept of the 'abject'. Drawing on Jacques Lacan's theory of the mirror stage, when a child not only becomes distinctly aware of her or his sense of separation from the rest of the world when looking in a mirror but also of the world as a place consisting of representational objects, Kristeva's 'abject' suggests an interesting link between purely semiotic and symbolic language. According to Deborah Covino, '[1]ike the semiotic, then, the abject is also what is suppressed and repressed within and through symbolic language' (Covino, 2004, p. 21). The Sogno can also be seen to 
exercise a similar shift from the semiotic to the symbolic. Pergolesi's fragmentary patterns and shapes divest themselves of their original symbolic meaning and become purely semiotic again, before acquiring new symbolic meaning through Auerbach's 'suppression' and 'repression' of the material. Auerbach's reflection of Pergolesi's music in this new context creates a mirror image that is both strange and familiar-an 'abject' form that is powerful precisely because it 'is not perfectly brought under the control of the Symbolic or Paternal Order' (Covino, 2004, p. 21). ${ }^{6}$

\section{Case Study 2: Hidden Disunities and Uncanny Resemblances in the music of}

\section{Michael Nyman}

How, then, can the uncanny resemblances that furnish the surface structure of Lera Auerbach's Sogno di Stabat Mater be understood in wider context? I shall now attempt to explain this in relation to George Lipsitz's concept of 'families of resemblance'. While Lipsitz's theory relates to a very different area-the study of cultural appropriation of Hispanic Popular Music in Los Angeles Chicano communities during the 1970 s and 80 s - it can be (and indeed has been) applied to a whole range of different contexts (see, for example, Hill, 2000, pp. 138-47). Lipsitz's theory deals more directly with, as Sarah Hill puts it, "the crises of identity faced by marginalized others' (Hill, 2000, p. 138)—for which one could cite countless examples from across the globe. Its application to musical 'texts' divorced from any obvious sense of social or cultural reality is less common, however. My application of this idea therefore relates to the function of specifically musical rather than social texts. 
Lipsitz sees families of resemblance emerging from particular socio-cultural circumstances that are the direct consequence of modern industrialized society and its effects on 'dominant' and 'subordinated' groups (Lipsitz, 1987, p. 158). My argument is that further parallels can be drawn by relating this idea to the 'hegemonic' and 'marginal' texts of contemporary music: the lingua franca of musical modernismmost visibly shown in the atonal and serial works of the mid-twentieth-century. The voices from the margins reappear in the guise of quotation in order to question and challenge its authority. They appear in the form of vernacular styles (pop, folk, jazz and so on) or are drawn from the large body of works that constitute the historical past (such as Baroque music). Thus, to quote Lipsitz, 'improvised cultural forms and freefloating signs and symbols appropriated out of context can open up a world of play and desire previously constrained by the tyranny of master narratives' (Lipsitz, 1987, p. 176).

If Auerbach's appropriation of the 'signs and symbols' of Baroque music does not carry the same political resonance as that of popular music in East Los Angeles, then what message does it carry? There is a certain sense in which the Stabat Mater's appearance in Sogno serves at the very least to render the 'master narrative' of twentieth century modernism — atonality and chromaticism—ambiguous and unstable. The relationship between the two is arguably more dialectical and dialogical than subversive or disruptive, however. In fact, further connections can be drawn between these seemingly diverse examples of musical appropriation. Musical quotation used by Auerbach and other composers fits Lipsitz's description (drawn from Octavio Paz) of a postmodern culture whose 'residue of many historical cultures [floats] above us, "ragged but beautiful", "never quite existing and never quite vanishing"' (Lipsitz, 1987, p. 159). 
A strange sense of unity through disunity — an uncanny resemblance-is communicated in Auerbach's Sogno di Stabat Mater. Families of resemblance are predicated on notions of 'bifocality or reciprocity of perspectives', the 'juxtaposition of multiple realities' and 'intertextuality [and] inter-referentiality' (Lipsitz, 1987, p. 162). Auerbach also draws on the stylistic resemblances that exist between her own musical language and that of an existing work from the eighteenth century to fashion a 'unity [out] of disunity' (Lipsitz, 1987, p. 160). In very much the same way that Chicano rock ' $n$ ' roll musicians from Los Angeles 'engage in an uneasy dialogue' with American popular culture, 'cultivating their bifocality as a means of expressing and arbitrating their real social marginality' (Lipsitz, 1987, p. 168), Auerbach also 'engages in an uneasy dialogue' with Pergolesi's Stabat Mater, as the title of her work suggests. Both examples therefore deal, albeit in different ways, with the postmodern principles of 'bifocality, juxtaposition of multiple realities, intertextuality, interreferentiality, and families of resemblance' (Lipsitz, 1987, p. 175).

The notion of 'families of resemblance' in relation to an entire body of work by a single composer can also be applied, in order to isolate, identify and describe the use of quotation or, indeed, self-quotation. A case in point is English composer Michael Nyman (b. 1944), known to draw on pre-existing works by Purcell, Mozart, Schumann, Schoenberg, and many others in his music, in addition to recycling his own material. ${ }^{7}$ Figure 8 illustrates such 'internal' connections in relation to works composed by Nyman between $1979-92$. The chart in Figure 8 is by no means exhaustive but it does provide a broad overview of the often labyrinthine pathways and interconnections between compositions in Nyman's oeuvre, highlighting innumerable examples of what might be described as single-authored multi-pieces: music that borrows or self-quotes material from previous compositions. (Clearly, in 
the case of Figure 8, 1992 has been chosen rather arbitrarily as a cut-off point: a number of arrows in the diagram would-could well continue beyond this point.)

\section{[Insert Figure 8 here]}

An example selected from Figure 8 will illustrate in general terms how these interrelationships might work in Nyman's oeuvre. His Taking a Line for a Second Walk, for two pianos (1986), is an arrangement of music originally written for a dance production for Houston ballet called Basic Black (1984). Basic Black also connects with the 'operatic duet' The Kiss (1985), music of which was then used in Nyman's opera Vital Statistics (1987), and later reworked in another opera Facing Goya (2000). In fact Basic Black is derived from an earlier composition Think Slow, Act Fast (1981), originally written for the Dutch contemporary ensemble Hoketus. Music for Basic Black also furnished the material for Nyman's later Concerto for Saxophone Quartet and Orchestra (2001), thus indicating that quite extensive time-spans can separate works that share the same (or similar) material.

Nyman's oeuvre may therefore be seen to function as a kind of family network not unlike Lipsitz's families of resemblance, due to the intertextual nature of these relationships. Nyman has also used the expression 'musical family tree' to describe relationships between his compositions (Nyman, 1988). To focus on one 'branch' of this family tree, as shown in Figure 9- the Concerto for Harpsichord (1995) borrows from the Convertibility of Lute Strings (1992) and Tango for Tim (1994), both for solo harpsichord. The latter work is itself based on music from the soundtrack to the film $A$ La Folie (1994). The Convertibility of Lute Strings draws on material derived from Nyman's first chamber opera The Man Who Mistook His Wife for a Hat (1986), while the Concerto also subsequently spawned another work for solo harpsichord, Elisabeth 
Gets Her Way (1996). It is therefore helpful to view Nyman's entire oeuvre as consisting of one large 'text', rather in the way that Laurence Sterne's novel Tristram Shandy or Miguel de Cervantes's Don Quixote become rich repositories for everything their authors wish to write about (in fact, one of Nyman's unfulfilled projects was has been to turn Sterne's novel into an opera)..$^{8}$ Viewing a composer's oeuvre in such a way encourages the perception of a large text as constituting any number of intertexts, and supports Derrida's famous dictum that '[there] is nothing outside of the text [there is no outside-text; "il n'y a pas de hors-texte"]' (Derrida, 1976, p. 158).

[Insert Figure 9 here]

Figure 9 'Harpsichord’ 'intertexts' in Michael Nyman's music.

The unity of Nyman's entire output is therefore tied to the concept of the work as a family of associations. Within this greater unity, Nyman admits and employs a number of external elements - 'referential texts' as they might be termed. These 'referential' intertexts serve to, as it were, nourish and replenish the body of work. Without wishing to push the analogy too far (and falling prey to a stereotypical notion of gender in the process), the family tree idea can be applied by Nyman in the following way: 'Paternal' forms are established by admitting other composers' works into the textual network. Because they emerge from outside the body of work they are effectively extrinsic and passive until absorbed and integrated into the composer's sound world and musical language. They then start to form an active part in the network's function. Such 'paternal' forms have included, in Nyman's case: Monteverdi, Bull, Biber, Purcell, Mozart, Chopin, Schumann, Wagner, Brahms, Schoenberg and Webern. 
Some of these allusions are of a peripheral nature and remain generally passive if they either inform only part of a work or are transformed in such a way that the original's context and function is no longer strictly relevant, as in a four-note sequence derived from Monteverdi used by Nyman in his Water Dances (1984). At the same time, and of arguably more importance, are texts that spawn other texts. They provide the means by which a text may be reproduced in another, and the pattern replicated ad infinitum. These 'maternal' texts directly generate other texts. Some serve to endlessly animate and expand the process, while conversely the lifespan of other musical ideas are short in comparison.

Nyman weaves some of these generic patterns into a number of different musical contexts, as shown in the following figures. The first example consists of an accented syncopated figure that typically oscillates between the tonic and its upper auxiliary note, or between the tonic and its mediant (see Figures 10a, b and c).

Making an early appearance in Masterwork Samples (based on music for The Masterwork/Award-Winning Fishknife, 1979), this rhythmic/melodic figure is used to very different ends in the viola line of 'To the Edge of the Earth' from The Piano soundtrack (1993), and also in the aria 'How Do I Know You Know' from Act 1, scene 2 of Facing Goya (2000). In its 'original' version, the pattern supports rhythmically active and energetic movement, which is also produced in an excerpt from Facing Goya (Figure 10c). However, in 'To the Edge of the Earth' the same figure is used to create a gently rocking and far more lyrical motion. Nyman thus imbues such musical tropes with an ability to adapt and change character, function and meaning, depending on the musical, dramatic or visual context in which they are used.

\section{Insert Figure 10a here: Theme from the Masterwork Samples}


Figure 10a Nyman's theme from the Masterwork Samples.

Insert Figure 10b here: The Piano: 'To the Edge of the Earth'

Figure 10b 'To the Edge of the Earth' from The Piano soundtrack.

Insert Figure 10c here: Facing Goya: 'How Do I Know You Know'

Figure 10c ‘How Do I Know You Know’ from Facing Goya.

Generic harmonic patterns are also developed in similar fashion, such as the four-chord sequence that forms the basis of the main section of Nyman's Saxophone Concerto, Where the Bee Dances (1991), as shown in the first chord pattern in Figure 11. This pattern consists of the sequence: $F$ major seventh, $G$ dominant seventh, $C$ major ninth and A minor seventh formed underneath a simple melodic descent from $\mathrm{E}$ to $\mathrm{C}$ via D over a pedal C. Nyman has noted that the original sequence came from the soundtrack to Michael Eaton's film Frozen Music (1983), where it accompanies a distinctive, almost pentatonic, melodic line. The harmonic motion towards the tonic is strongest in this version, where Nyman may have felt that the film's score required a more direct the musical languageapproach required a more direct treatment. Another, more basic three-chord variation of this pattern appears at the beginning of a work dating from around the same time - a setting of texts from Sterne's Tristram Shandy called Love is Certainly, at Least Alphabetically Speaking (1983), as shown in the second chord sequence in Figure 11. The chord pattern also reappears in Nyman's more recent settings of Pietro Aretino's erotic sonnets, I Sonneti Lussuriosi (Eight Lust Songs), for female voice and orchestra, composed in 2008.

Insert Figure 11 here 
Figure 11 Two similar chord sequences from Nyman's Where the Bee Dances and Love is Certainly, at Least Alphabetically Speaking.

An additional connection is seen in the fact that the opening section from the Saxophone Concerto- which does not incorporate the aforementioned chord sequence — is taken from the similarly entitled 'Where the Bee Sucks' from the soundtrack to Peter Greenaway's film Prospero 's Books (1991), a film which also illustrates (among other things) the inherent intertextuality of (written) texts. Thus we have a series of works connected through unrelated material- 'distant relatives' in the family tree, as it were. Some patterns become more specific in character, gradually acquiring the shape of clearly identifiable themes. For example, one melodic feature of Nyman's style during the early 1990s consisted of a melodic type that would often set off from an initial downbeat, reaching up to — and sometimes beyond - an octave. A syncopated effect was often added to this phrase by tying the first note of both the third and fourth semi-quaver groups to its preceding note, as heard in the opening theme from the String Quartet No. 3 (1990) (see Figure 12). In this example from the quartet the idea assumes a central thematic role and the context is lyrical and somewhat introspective in nature. Thus the theme's potential, a paradox given its rising trajectory, is often used to signify introversion and self-doubt, as also heard in 'Outside Looking In' from the soundtrack to Christopher Hampton's film Carrington (1994). Its appearance in Carrington came as a result of Frampton's-Hampton's request, allowing Nyman to simply reproduce and continue the recomposing process as the film's cues demanded. But on other occasions its function is subsidiary and its expressive nature is changed, such as in its more dynamic rhythmic manifestation in a horn line heard in For John Cage for brass consort (1992).

\section{[Include Figure 12 here]}


Figure 12 Scale-like pattern in Nyman's String Quartet No. 3.

These examples merely show how families of resemblance can underpin a composer's oeuvre in general. In constructing melodic and rhythmic figures, one can see that a composer such as Nyman often draws upon a pool of individual types and topics. These are not so much overt quotations or references as flexible units that can easily be varied and manipulated according to context. An idea which plays a marginal role in one work may assume a more central role in another, its features magnified and potentialities explored in greater depth. Variations existing between compositions often reflect the variations applied within them. Variations upon variations thus appear, creating a seemingly endless fractal spiral of relationships.

\section{Conclusion}

In composing either single works that engage in uneasy dialogical relationships, such as Auerbach's Sogno di Stabat Mater, or building an entire body of works based on the idea of families of resemblances, contemporary music has attempted to integrate the past and present in a manner which lies in stark contrast to high modernism's use of quotation in the 1960s and 70s. Nyman and Auerbach are certainly not alone in adopting such approaches. In a passage from his autobiography Hallelujah Junction, American postminimalist composer John Adams quotes Harold Bloom's dictum 'to imagine is to misinterpret', before going on to say that: 
[every] reading of another work of art, whether it comes from a distant, unfamiliar culture or from one's own backyard, is a de facto misinterpretation. Appropriation is in fact the norm among societies. Since earliest recorded time one culture has intermingled its art with that of another, and that intermingling by its very nature must be subject to misapprehension, misappropriation, even misuse. Nevertheless, cross-fertilization more often than not is a willing, even enthusiastic act of mutual sharing. Like the strengthening of a species through genetic variety, a crossbreeding of artistic traditions, creatively engaged, can produce robust new genres. (Adams, 2011, p. 309)

In analysing explicit examples of quotation, such as those found in the above analyses examplesabove, it is necessary to locate the intertext both within and outside its immediate context. In his study of European minimal music, Maarten Beirens has described these aspects as 'intra- and extra-musical' (Beirens, 2005, p. 414). Intramusical refers to the quotation's function within a particular composition, whereby 'a "dialogue" emerges between the original material and the way it has been processed, modified, juxtaposed with other material and integrated into a formal structure' (Beirens, 2005, p. 415). Extra-musical function indicates the nature of the quotation's relationship with the original source by means of identification, meaning and association (Beirens, 2005, pp. 414-15). I would therefore argue, along with Beirens, that the nature of a text's interaction with its intertexts is crucial in gaining an understanding of a composer's musical language.

While the use of collage and juxtaposition sets up a conflict between the primary source and its new location, the examples cited in this article are integrated on the surface of the music and embedded in the composer's language while a sense of disunity or conflict may still lie hidden underneath. The use of such past styles connect with postmodern and (in Nyman's and Adams's case) postminimalist styles 
by drawing on associative patterns - the use of ostinati, chaconne bass, tonallyderived chord progressions, recognizable melodic shapes, variation forms, and so on - that often belongs to the music that quotes and is quoted. However, there is clearly some attempt to manipulate and treat the pre-existing material in some way. This synthesis is certainly not designed to be as smooth and effortless as Procol Harum's 'A Whiter Shade of Pale'. Thus the challenge for the contemporary composer who employs quotation in this integrated sense is, according to Beirens, 'to provide a new musical context for the "borrowed" material that takes at least some of these associations into account and/or uses it to articulate some musical or extramusical meaning' (Beirens, 2005, p. 403), while the challenge for the musicologist is to identify the most relevant analytical methods and aesthetic contexts in which this music may be understood.

\section{References}

Adams, J. (2011). Hallelujah junction: Composing an American life. London: Faber and Faber.

Allen, G. (2000). Intertextuality. London: Routledge.

Ap Sion, P. (2007). The music of Michael Nyman. Aldershot: Ashgate Publishing.

Auerbach, L. (2008). Sogno di Stabat Mater (score). Hamburg: Musikverlag Hans Sikorsi GmbH \& Co.

Auerbach, L. (2012). Lera Auerbach: 'Dialogues on Stabat Mater' given Kyrgyzstani premiere. Sikorski News Archive (February). Retrieved December 1, 2013, from http://www.sikorski.de/5962/en/lera_auerbach_dialogues_on_stabat_mater_given_kyr gyzstani_premiere.html

Bakhtin, M. M. (1981). The dialogic imagination: Four essays (C. Emerson and M. Holquist, Trans.). Austin: University of Texas Press.

Beirens, M. (2005). The identity of European minimal music. Unpublished Doctoral thesis, Catholic University Leuven.

Covach, J. (1997). Progressive rock, 'Close to the Edge', and the boundaries of style. In J. Covach and G. M. Boone (Eds.), Understanding rock: Essays in music analysis (pp. 3-32). Oxford: Oxford University Press. 
Covino, D. C. (2004). Amending the abject body: Aesthetic makeovers in medicine and culture. Albany: State University of New York Press.

Derrida, J. (1976). Of grammatology (G. C. Spivak, Trans.). Baltimore: Johns Hopkins University Press.

Derrida, J. (1991). From 'Des Tours de Babel'. In P. Kamuf (Ed.), A Derrida reader: Between the blinds (pp. 243-253). New York: Columbia University Press.

Gillett, C. (1983). The sound of the city (2nd ed.). London: Souvenir Press. (First edition published 1970.)

Griffiths, P. (2010). Modern music and after (3rd ed.). Oxford: Oxford University Press. (First edition published 1981.)

Heile, B. (2006). The music of Mauricio Kagel. Aldershot: Ashgate Publishing.

Hill, S. (2000). Families of resemblance: Welsh popular music and other marginalia. Welsh Music History, 4, 138-147.

Hutcheon, L. (1985). A theory of parody. London: Routledge.

Kosman, J. (2010). Review of Sogno di Stabat Mater. San Francisco Chronicle (2 November). Retrieved December 1, 2013, from

http://www.musicsalesclassical.com/composer/work/44971

Kramer, L. (1990). Music as cultural practice, 1800-1900. Berkeley: University of California Press.

Kramer, L. (2002). Musical meaning: Toward a critical history. Berkeley: University of California Press.

Kristeva, J. (1980). Desire in language: A semiotic approach to literature and art (T. Gora, A. Jardine and L. S. Roudiez, Trans; L. S. Roudiez, Ed.). New York: Columbia University Press.

Kristeva, J. (1986). The Kristeva reader (T. Moi, Ed.). New York: Columbia University Press.

Lipsitz, G. (1987). Cruising around the historical bloc: Postmodernism and popular music in East Los Angeles. Cultural Critique, 5, 157-177.

Metzer, D. (2003). Quotation and cultural meaning in twentieth-century music. Cambridge: Cambridge University Press.

Middleton, R. (1990). Studying popular music. Milton Keynes: Open University Press.

Nyman, M. (1988). Liner notes to The Kiss and Other Movements (EEGCD40).

Osmond-Smith, D. (1985). Playing on words: A guide to Luciano Berio's Sinfonia. London: Royal Musical Association. 


\section{Notes}

[1] Procol Harum's single 'A Whiter Shade of Pale' (Deram 7507) was released in May 1967.

[2] Percy Sledge's single 'When a Man Loves a Woman' (Atlantic 2326) was released in April 1966.

[3] Wendy [then Walter] Carlos's LP Switched-On Bach (Columbia Masterworks MS7194) was first released in March 1968.

[4] Pergolesi's Stabat Mater is also used extensively in Lars von Trier's disturbing film Dogville (2003) to evoke an unsettling and uncanny atmosphere.

[5] Graham Allen defines heteroglossia as 'language's ability to contain within it many voices, one's own and other voices' (Allen, 2000, p. 29).

[6] Jacques Derrida's essay 'Des Tours de Babel' suggests yet other ways of 'reading' Auerbach's music in this context (see Derrida, 1991, pp. 243-253). Thanks to Lauren Redhead for drawing my attention to these connections.

[7] Part of this article draws from previous research contained in my book The Music of Michael Nyman (see ap Siôn, 2007, pp. 59-80).

[8] Director Michael Winterbottom in fact used Nyman's music in his film adaptation of Sterne's novel, A Cock and Bull Story (BBC Films, 2005), 